\title{
Do birds in flight respond to (ultra)violet lighting?
}

\author{
Roel May ${ }^{1 *} \mathbb{0}$, Jens Åström ${ }^{1}, \varnothing y v i n d$ Hamre $^{1}$ and Espen Lie Dahl ${ }^{1,2}$
}

\begin{abstract}
Background: Concerns for bird collisions with wind turbines affect the deployment of onshore and offshore windpower plants. To avoid delays in consenting processes and to streamline the construction and operation phase, functional mitigation measures are required which efficiently reduces bird mortality. Vision is the primary sensory system in birds, which for a number of species also includes the ultraviolet spectrum. Many bird species that are known to collide with offshore wind turbines are sensitive in the violet or ultraviolet spectrum. For species that are mainly active at lower ambient light levels, lighting may deter birds from the lit area. Utilizing (ultra)violet lights may in addition not disturb humans. However, we do not know whether UV-sensitive birds in flight actually respond behaviourally to UV lights.
\end{abstract}

Methods: We therefore tested the efficacy of two types of lights within the violet ( $400 \mathrm{~nm}$ ) and ultraviolet (365 nm) spectrum to deter birds from the lit area. These lights were placed vertically and monitored continuously between dusk and dawn using an avian radar system.

Results: Relative to control nights, bird flight activity (abundance) was 27\% lower when the ultraviolet light was on. Violet light resulted in a 12\% decrease in overall abundance, and in addition, a vertical displacement was seen, increasing the average flight altitude by $7 \mathrm{~m}$. Although temporal changes occurred, this effect persisted over the season below $40 \mathrm{~m}$ above sea level.

Conclusions: Although the results from this pilot study are promising, we argue there still is a long way to go before a potentially functional design to mitigate collisions that has proven to be effective in situ may be in place.

Keywords: Avian radar, Displacement, Habituation, Mitigation, Seabirds, Ultraviolet, Wind turbine

\section{Background}

To satisfy the energy demand and to increase the share of renewable resources wind energy deployment has increased (Intergovernmental Panel on Climate Change 2011). Concerns about the impact of wind energy on birdlife, through collisions, disturbance and habitat loss, have at the same time become more acute (Gove et al. 2013). Because of the fast rate of deployment, it has become challenging to verify impacts on birdlife and develop ways of mitigating these (Gove et al. 2013). These concerns can be an economic problem for the energy industry and for society as a whole (Cole 2011), and

\footnotetext{
*Correspondence: roel.may@nina.no

${ }^{1}$ Terrestrial Ecology Department, Norwegian Institute for Nature Research (NINA), Trondheim, Norway

Full list of author information is available at the end of the article
}

reduces the predictability in the planning and consenting processes. Collision with wind turbines is the main cause for direct bird mortality at wind-power plants. However, mitigating wind-turbine induced bird mortality is particularly complicated because it may originate from collision, disturbance and barrier effects that are site- and species-specific (Marques et al. 2014; May et al. 2015). Concerns regarding collision risk have stimulated research to quantify these effects post-construction, and to predict the extent of effects pre-construction in connection with the planning of new wind-power plants. Developing and testing techniques for mitigating collision risk, however, still need to be improved (Intergovernmental Panel on Climate Change 2011). It is paramount to develop practical and functional tools, products and other measures that reduce bird mortality 
related to offshore and onshore wind energy production, in order to avoid delay in consenting processes and to streamline the construction and operation phase while preserving bird populations at those sites.

In practice, it is normally a very long step from documenting the extent of the impact caused by the construction and operation of wind-power plants to successful mitigation (Lehman et al. 2007). The main reason why mortality-reducing tools are not already developed is due to the challenges in assessing the effectiveness of such tools in situ (May et al. 2015). The detected number of birds killed at a wind-power plant is often too low, due to removal by scavengers or observer bias, to be used as the only criteria to assess a measure's effectiveness within a limited timeframe. Studies of behavioural responses, such as avoidance and/or reduced activity in the vicinity of the turbines due to the measures tested, are therefore necessary (May et al. 2017). Due to the relatively short history of wind energy production, there is a lack of comparative studies of scientific quality (May et al. 2015). Investigations in this field are connected with several uncertainties such as statistical significance, time required to get reliable results, number of trials/turbines, costs and practicalities, especially in connection with offshore installations. Still, in situ testing of promising pathways to mitigate impacts are important to increase our knowledge incrementally. One promising approach is that of utilizing the sensitivity of many bird species within the (ultra)violet spectrum to deter birds from turbines using ultraviolet or violet (UV) lighting (May et al. 2015). Visual deterrence using UV lights will be most effective at low light levels, and may therefore mainly help to mitigate collisions of nocturnal and crepuscular flight activity between dusk and dawn. Still, to-day there exists no proof-of-concept whether birds are in fact deterred in flight from areas lit up by (ultra)violet light (but see Hunt and McClure 2015).

Vision is the primary sensory system of birds, with a higher acuity and a generally lower temporal resolution than humans. It will therefore be important to take into account avian visual ecology when designing mitigation measures (Martin 2011). Blackwell and Bernhardt (2004) and Blackwell et al. $(2009,2012)$ empirically showed that birds' visual systems (visual acuity and visual fields) enable them to respond behaviourally to lighting regimes (no, constant or pulsating lights) in approaching objects (aircraft and vehicle). Birds have tetrachromatic colour vision and spectral sensitivities of photoreceptors between 320 and $700 \mathrm{~nm}$ (Osorio and Vorobyev 2008). Birds with highly sensitive UVS-cones and birds with the less UV-sensitive VS-cone variant are all sensitive to UV light (Lind et al. 2014). Both gulls and passerines are sensitive within the ultraviolet spectrum $(355-380 \mathrm{~nm}$ :
Ödeen et al. 2010; Lind et al. 2014). Gulls are species of concern for collision with offshore wind turbines given their ecology (Furness et al. 2013). Raptors and owls, including Burrowing Owl (Athene cunicularia) and Golden Eagle (Aquila chrysaetos), seabirds and waders, and gallinaceous birds have (ultra)violet single cones with sensitive functions that peak in the violet spectrum (402426 nm: Håstad et al. 2005; Ödeen and Håstad 2013; Doyle et al. 2014; Lind et al. 2014). At onshore windpower plants, raptors and owls are often perceived to be vulnerable to collision mortality (Drewitt and Langston 2008). Typically, the lower limit of the human visible spectrum is $390 \mathrm{~nm}$. Given these differences, it may be possible to develop mitigation measures without disturbing humans. Here we have to keep in mind that objects reflecting or emitting ultraviolet light may, besides having an illumination effect, be viewed as a different colour to the avian eye (Cook et al. 2011). Although the avian eye is better than ours-in avoiding obstacles or chasing prey in fast flight-its performance decreases with falling light levels more so than for humans (Jarvis et al. 2002), perhaps even during rain or cloudy weather. The function of ultraviolet vision in birds is thought to be related to orientation, foraging and signalling (Bennett and Cuthill 1994). Ultraviolet cones in the eyes of birds have been shown to be receptive to both visual and magnetic information (Bischof et al. 2011). Although monochromatic ultraviolet light $(373 \mathrm{~nm}$ ) could disrupt natural orientation behaviour in European Robins (Erithacus rubecula) (Wiltschko et al. 2014); these two mechanisms (vision and magnetoreception) were found to be independent of each other. Birds may be able to separate visual and magnetic information derived from ultraviolet cones through light at other wavelengths, magnetite-based receptors in the beak, and/or optic flow during movement (Bischof et al. 2011; Wiltschko et al. 2014). In fact, Gauthreaux and Belser (2006) summarize how filtering out all wavelengths but for ultraviolet light essentially eliminated migratory bird mortality at ceilometers. Also, Poot et al. (2008) showed that nocturnally migrating birds were least disoriented from blue lights $(455 \mathrm{~nm})$.

Although it might be tempting to operationalize innovative mitigation tools solely based on theory, pre-development ex situ feasibility studies as well as post-development in situ testing are important prior to deployment. Such assessments ensure that unsuccessful techniques can be eliminated in an early phase and the effectiveness of innovations can be documented. Lights within the UV spectrum $(\leq 400 \mathrm{~nm})$ with low power input are now available. Martin $(2011,2012)$ argues that the sensory ecology in birds is more attuned to observing and responding to impulses from the ground. We therefore envision utilizing UV lights that sweep upwards 
during nighttime encircling the rotor swept zone to exclude birds from this risky area (i.e. light-fence). UV lights are invisible to the human eye but may deter nocturnal birds from entering the rotor swept zone without creating visual nuisance for humans. However, there are potential health hazards connected with UV light, which can be harmful to peoples' (and birds') eyesight that will have to be taken into account. Such a system must therefore be constructed in such a way that it will be safe to the public, which means that it must be mounted out of reach of people (well above the base), with the light beam pointing upwards, perhaps in the form of pulsating beams. However, before commencing with intricate engineering to conceive optical deterring devices to birds, it will be important to know beforehand whether bird species that are sensitive within the (ultra)violet spectrum actually respond behaviourally to UV light. As a feasibility study, we therefore explored whether birds in flight respond to ultraviolet/violet lights. In theory, UV lights may either lead to behavioural evasion of the birds in flight (partial avoidance, with a shift in their flight path) or displacement from the lighted area (leading to reduced activity) (May 2015). Alternatively, birds might also be attracted to the UV lights leading to opposite results. The main hypothesis for testing the possible efficacy of UV lights was that birds would refrain from flying through the area of light. This hypothesis leads to the following research questions: (1) to which extent UV light leads to a proportional reduction in the number of recorded flights within pre-specified distances and altitudes around the lighted area, and (2) to which extent recorded flights verifiably change altitude, and at which distance? These effects may in addition change over time due to positive (getting used to the lights) or negative (avoiding the area altogether) habituation.

\section{Methods}

\section{Study site and experimental design}

This feasibility study was done ex situ, i.e. outside the wind-power plant, testing for possible responses in birds to UV light. To ensure adequate confidence in the outcomes of this test, two UV LED lights (Type EXT400; Martin, Denmark) were placed vertically on top of a $2.5 \mathrm{~m}$ mast located near Veiholmen on the island of Smøla $\left(63.50961^{\circ} \mathrm{N}, 7.9761^{\circ} \mathrm{E}\right)$ during spring (March-May 2014). Veiholmen is a fishing village located on a group of tiny islands in the northern part of Smøla Municipality in Møre og Romsdal county, Norway. From the onset, the lights, one within the violet $(400 \mathrm{~nm})$ and one within ultraviolet $(365 \mathrm{~nm}$ ) wavelength spectrum (see Additional file 1: Figure S1 for spectrograms), were used with maximized irradiance and a beam width of $62^{\circ}$. The nominal output of both lights was prior to operation increased to
$700 \mathrm{~mA}$ (from $500 \mathrm{~mA}$ ); resulting in an increased irradiance of 10 and $24 \%$ for respectively 365 and $400 \mathrm{~nm}$ (respectively: 0.169 and $0.646 \mathrm{Watt} / \mathrm{m}^{2}$ ). The nominal output gives a safety distance threshold for humans of circa $8 \mathrm{~m}$ (Martin pers. comm.). The experimental design was approved by the Civil Aviation Authority, municipality of Smøla and the private landowner. The lighting regime alternated between one of the two lights $(365 \mathrm{~nm}$ : Tuesdays, Saturdays; $400 \mathrm{~nm}$ : Thursdays, Sundays) with intermediate control-days without any lighting (Mondays, Wednesdays, Fridays). Thereafter the lights were sequentially on every other day for 2 months during dawn/dusk and nighttime (17:00-08:00). During daytime, UV lights were expected to be ineffective due to exceeding levels of UV light from the sun and were therefore not activated. Background UV light levels were measured continuously at the avian radar van (see below) using an UVA sensor (315-400 nm; Type SKU 421/I; Skye Instruments, United Kingdom).

\section{Avian radar monitoring}

Bird flight movements in the vicinity of the UV lights was recorded continuously (24/7) using a vertical Frequency Modulated Continuous Wave (FMCW) radar (coherent X-band radar with $20^{\circ}$ beam width and $1^{\circ}$ beam height) to obtain best coverage of data collection with the area of interest. The FMCW forms an integral part of the ROBIN avian radar system (ROBIN B.V., the Netherlands), enabling automatically tracking and storing all bird movement information in a database (including e.g. timestamp, georeference, radar cross section). The avian radar system was stationed circa $370 \mathrm{~m}$ from the UV lights and scanning the sector in the same azimuth $\left(17^{\circ}\right)$. At this distance, the beam width covers an area of circa $65 \mathrm{~m}$ on either side of the lights and detectability is not hampered by detection loss over range. Utilization of this avian radar followed the permit given by the Norwegian Communications Authority, and was locally approved by the municipality and the private landowner. Radar monitoring commenced in the period 18 March 2014 through to and including 31 May 2014 (75 days). Due to technical complications, the radar was malfunctioning in five distinct periods (20-25 March (6 days); 6-15 April (10 days); 3-5 May (3 days); 24-27 May (4 days); 5 June (1 day)). Horizontal radar data could not be recorded in the areas surrounding the UV lights due to extensive amounts of ground clutter. Weather permitting and when practically feasible, groundtruthing of radar tracks was done during dawn and dusk. During these periods, radar tracks were groundtruthed by visually observing bird species. Prior to each groundtruthing session, the lights were checked whether they were fully functional (by checking an indication LED underneath the lamps). 


\section{Statistical analyses}

Behavioural changes in (log-transformed) flight altitude were assessed by comparing five a priori defined models using the lmer function of the lme4 library in the statistical software programme $\mathrm{R}$ version 3.2.2 ( $\mathrm{R}$ Core Team 2015). All models included random effects to control for temporal autocorrelation by clustering over each unique track, for spatial patterns in altitude selection by including distance from the radar (i.e. range) as a random slope, and for daily varying environmental conditions by clustering over night-of-year (NOY). NOY was defined as $24-\mathrm{h}$ periods from noon to noon. Spatial patterns in altitude selection-unrelated to the actual test-could occur due to adjusted flight altitudes above land masses versus over sea and the presence of a fish landing close to the radar site. Also, the lights produce cones covering an increasing circular area with increasing altitude. However, dependent on the way birds see when in flight (Martin 2011), an effect does not necessarily have to be limited to this cone alone. The a priori models were defined to capture various responses: (1) no effect including only the intercept; (2) behavioural response to the UV lights irrespective of distance, when the bird perceives the light ahead (UV_TYPE); (3) increasing behavioural response towards the UV lights, when the bird enters the light cone (UV_TYPE*Distance); and (4) and (5) including potential habituation to the UV lights for the last two models ("NOY). These models were compared for overall likelihood of fit using log-Likelihood tests.

Effects of the UV lights on flight activity was assessed within the volume directly surrounding the UV lights, including only data within $50 \mathrm{~m}$ in both distance and altitude. Flight activity, defined as the number of radar track points per $10 \mathrm{~m}$ intervals in both distance and altitude per night represented the response variable in the glmer function with a Poisson distribution. Due to the block design, both distance and altitude were included in the models as factors to control for spatial patterns in flight activity. All models included random effects to control for daily varying environmental conditions by clustering over night-of-year (NOY), as well as clustering by record to control for overdispersion. Five a priori defined contrasting models were assessed: (1) no effect including only a possible spatial pattern (Distance and Altitude) in activity; (2) UV light adjusted flight activity irrespective of both distance and altitude (UV_TYPE; no interaction); (3) UV light adjusted flight activity in distance (UV TYPE*Distance); (4) UV light adjusted flight activity in altitude (UV_TYPE*Altitude); (5) UV light adjusted flight activity both horizontally (UV_TYPE*Distance) and vertically (UV_TYPE*Altitude). While model 2 relates to full displacement, models 3 and 4 relate to partial displacement, respectively horizontally and vertically. Model 5 relates to responses when birds enter the light cone. To further assess potential temporal changes in effects over the season; we also ran the same models for each separate month.

All data collected during this study, as well as the $R$ scripts to run the analyses and produce the figures are included in this published article in the Additional file 2: uvdata.xlsx, Additional file 3: UV_analysis.R.

\section{Results}

During the monitoring period, the solar UV irradiance remained well above the UV-light irradiance during most of the day. Only during the midst of night, the UV lights emitted more light than the solar irradiance (Table 1). During night time, over $75 \%$ of all tracks were recorded below $50 \mathrm{~m}$ above sea level (a.s.l.), with an average flight altitude of circa $28 \mathrm{~m}$ a.s.l. (Fig. 1). Birds varied in their flight altitude also with respect to the local topography (Fig. 2). On the island (its land mass ranged between 330 and $460 \mathrm{~m}$ from the avian radar) where the UV-lights were placed, flight altitude increased slightly, irrespective of whether the lights were on or not. Tracks tended to lose altitude towards the avian radar position. This was likely due to the presence of a fish landing harbour close to the radar. We found, however, neither a significant effect of weekday on the number of recorded tracks $\left(x^{2}=7.095\right.$, $\mathrm{df}=6, p=0.312)$ nor on flight altitude $\left(\mathrm{x}^{2}=10.059\right.$, $\mathrm{df}=6, p=0.122$ ) due to any human activity over the week alternating between workdays and weekends. However, all models included a random grouping on Julian day to control for any temporal effects external to the design. Most groundtruthed bird-tracks were large gull species [e.g. Greater Black-backed Gull (Larus marinus) and European Herring Gull (Larus argentatus)]. Most observed birds flew below $10 \mathrm{~m}$ a.s.l. apart from small gull species [e.g. Common Gull (Larus canus), Black-legged Kittiwake (Rissa tridactyla)] (Table 2). All of these species are sensitive within the ultraviolet spectrum (Ödeen and Håstad 2013). The cumulative distribution function of the range-corrected mass (i.e. radar cross section) of groundtruthed birds was not significantly greater than the observed birds included in the analyses (two-samples Kolmogorov-Smirnov test: $D=0.0002, p=1$ ). However the lower tail of the cumulative distribution function was significantly different $(D=0.244, p<0.001)$. This was due to the difficulty to groundtruth smaller-sized birds including common species as Meadow Pipit (Anthus pratensis), Wheatear (Oenanthe oenanthe), Common Snipe (Gallinago gallinago) and Golden Plover (Pluvialis apricaria) (Bevanger et al. 2010) over larger distances. While the former two are sensitive within the ultraviolet spectrum, the latter two species are sensitive within the violet spectrum (Ödeen et al. 2010, 2011). 
Table 1 Measured UVA (315-400 $\mathrm{nm}$ ) solar radiance (Watt/ $\mathrm{m}^{2}$ ) through the day during three spring months at Veiholmen, Smøla, Norway

\begin{tabular}{|c|c|c|c|c|c|c|}
\hline \multirow[b]{2}{*}{ Hour } & \multicolumn{3}{|c|}{$365 \mathrm{~nm}$} & \multicolumn{3}{|c|}{$400 \mathrm{~nm}$} \\
\hline & March & April & May & March & April & May \\
\hline 0 & 0.02 & 0.02 & 0.02 & 0.02 & 0.02 & 0.02 \\
\hline 1 & 0.02 & 0.02 & 0.02 & 0.02 & 0.02 & 0.02 \\
\hline 2 & 0.02 & 0.02 & 0.03 & 0.02 & 0.02 & 0.03 \\
\hline 3 & 0.02 & 0.02 & 0.11 & 0.02 & 0.02 & 0.11 \\
\hline 4 & 0.02 & 0.03 & 0.55 & 0.02 & 0.03 & 0.55 \\
\hline 5 & 0.02 & 0.30 & 1.76 & 0.02 & 0.30 & 1.76 \\
\hline 6 & 0.09 & 1.31 & 3.53 & 0.09 & 1.31 & 3.53 \\
\hline 7 & 0.83 & 3.19 & 6.33 & 0.83 & 3.19 & 6.33 \\
\hline 8 & 2.58 & 5.41 & 9.20 & 2.58 & 5.41 & 9.20 \\
\hline 9 & 4.65 & 7.65 & 11.04 & 4.65 & 7.65 & 11.04 \\
\hline 10 & 6.26 & 9.86 & 11.95 & 6.26 & 9.86 & 11.95 \\
\hline 11 & 8.59 & 10.94 & 13.53 & 8.59 & 10.94 & 13.53 \\
\hline 12 & 8.98 & 11.52 & 13.79 & 8.98 & 11.52 & 13.79 \\
\hline 13 & 8.83 & 11.99 & 13.13 & 8.83 & 11.99 & 13.13 \\
\hline 14 & 7.96 & 11.89 & 13.28 & 7.96 & 11.89 & 13.28 \\
\hline 15 & 7.23 & 9.36 & 10.71 & 7.23 & 9.36 & 10.71 \\
\hline 16 & 4.46 & 9.10 & 11.14 & 4.46 & 9.10 & 11.14 \\
\hline 17 & 2.65 & 6.60 & 9.52 & 2.65 & 6.60 & 9.52 \\
\hline 18 & 1.02 & 3.57 & 6.51 & 1.02 & 3.57 & 6.51 \\
\hline 19 & 0.17 & 1.42 & 3.69 & 0.17 & 1.42 & 3.69 \\
\hline 20 & 0.02 & 0.28 & 1.75 & 0.02 & 0.28 & 1.75 \\
\hline 21 & 0.02 & 0.03 & 0.50 & 0.02 & 0.03 & 0.50 \\
\hline 22 & 0.02 & 0.02 & 0.09 & 0.02 & 0.02 & 0.09 \\
\hline 23 & 0.02 & 0.02 & 0.02 & 0.02 & 0.02 & 0.02 \\
\hline
\end{tabular}

Lines and italic values indicate when solar radiance dropped below UV light irradiance at $5 \mathrm{~m}$ (dotted line), $10 \mathrm{~m}$ (solid line) and $20 \mathrm{~m}$ (bold and thick line) distance from the lights ( $365 \mathrm{~nm}: 0.169,0.042$ and $0.011 \mathrm{Watt} / \mathrm{m}^{2}$ respectively; $400 \mathrm{~nm}: 0.646,0.162$ and $0.040 \mathrm{Watt} / \mathrm{m}^{2}$ respectively). In grey the daytime period is indicated when the UV lights were off

The most parsimonious of the five a priori defined models of flight altitude, as determined by AIC, indicated that flight altitude increased when the UV-lights were on, and closer to the lights (Table 3, Fig. 3). Here, the effect of UV-light was stronger for the $400 \mathrm{~nm}$ wavelength where the average flight altitude at the UV-lights increased by $7 \mathrm{~m}$ (Control: $23 \mathrm{~m}$ a.s.l. [95\% CI 20-27 m]; $365 \mathrm{~nm}$ : $22 \mathrm{~m}$ a.s.l. [95\% CI $15-33 \mathrm{~m}$ ]; $400 \mathrm{~nm}: 30 \mathrm{~m}$ a.s.l. [95\% CI 21-44 m]) (Fig. 3). The next best model $(\triangle \mathrm{AIC}=3.26$, log-Likelihood-test: $x^{2}=8.74, \mathrm{df}=6, p=0.189$ ) also indicated that this effect slightly decreased over the season. A separate model, checking for the effect of the UV light inside versus outside the lighted cone (a form of BACI design), showed a significant effect of UV_TYPE inside the cone on flight altitude $\left(x^{2}=10.432, \mathrm{df}=2\right.$, $p=0.005$ ).

The most parsimonious model explained abundance of bird tracks within a $50 \times 50 \mathrm{~m}$ volume surrounding the UV-lights included UV_TYPE and Altitude (Table 4 and Figs. 1, 4). The second best model included UV_TYPE interactions with both distance and altitude (Table 4). Relative to control nights, abundance was reduced for altitudes below $30 \mathrm{~m}$ a.s.l. when exposed to light of $365 \mathrm{~nm}$. Instead for the $400 \mathrm{~nm}$ light, abundance increased above $30 \mathrm{~m}$ a.s.l. (Fig. 4). On average, UV-lights resulted in a 27 and $12 \%$ reduction of the number of track points for the 365 and $400 \mathrm{~nm}$ wavelength, respectively. Temporal effects could not be assessed directly due to the block modelling design. We therefore also estimated responses in flight activity for each month separately. For all months, the UV_TYPE*Altitude model was most parsimonious. In March, birds were displaced over most altitudes, significantly so for $10 \mathrm{~m}$ and $50 \mathrm{~m}$ respectively at the 365 and $400 \mathrm{~nm}$ wavelength (Fig. 5). In April this effect was still visible for the $365 \mathrm{~nm}$ wavelength, but less so for $400 \mathrm{~nm}$. In May, birds were mainly displaced at and below $30 \mathrm{~m}$ but used altitudes of $40 \mathrm{~m}$ and above more intensively. For the 365 and $400 \mathrm{~nm}$ wavelength the sign of the response changed direction over time above respectively an altitude of 30 and $20 \mathrm{~m}$, indicative of possible habituation. A separate model, checking for the effect the UV light inside versus outside the lighted cone (a form of BACI design), only showed a significantly reduced number of track points inside the cone $\left(\mathrm{X}^{2}=398.886, \mathrm{df}=1, p<0.001\right)$ irrespective of $\mathrm{UV}_{-}$ TYPE $\left(X^{2}=0.204, \mathrm{df}=1, p=0.903\right)$.

\section{Discussion}

This pilot study indicated that UV-light displaced birds in the vicinity of the light source. While birds were partially displaced in altitude by the emitted light at $365 \mathrm{~nm}$, birds mostly adjusted their flight altitude when subjected to light of $400 \mathrm{~nm}$. This displacement effect persisted over the season below 20-30 m a.s.l. but with increasing use of higher altitudes over time. This may indicate habituation over time, but could also just occur at the periphery of the lit area. Verification of this would require longterm studies and could not be determined in the current 


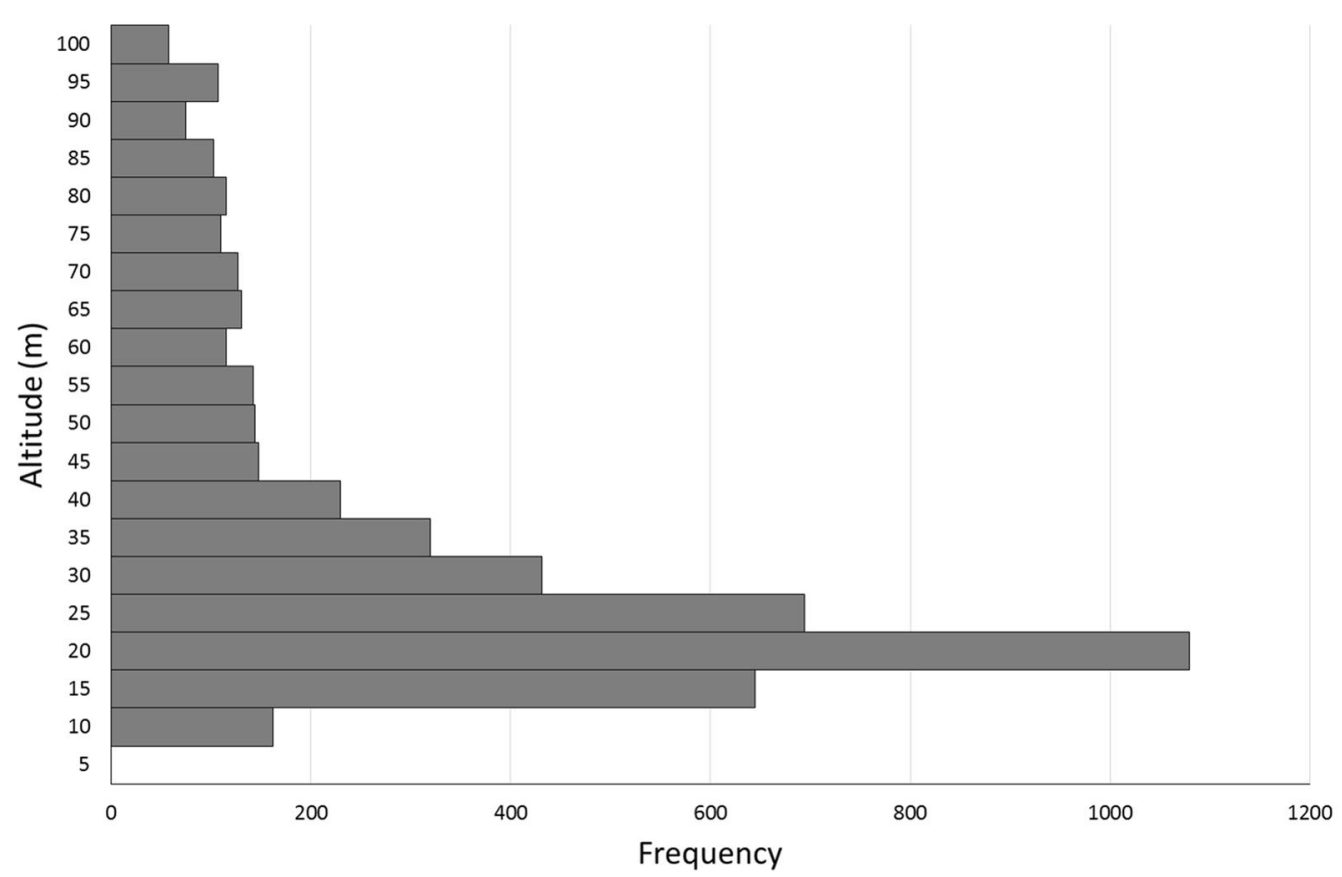

Fig. 1 Altitude distribution of avian radar tracks points within 320-420 m range from the avian radar

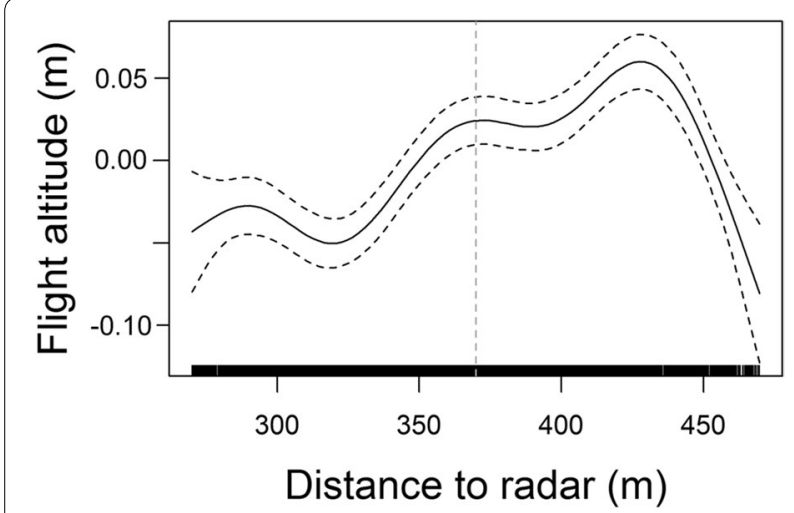

Fig. 2 Change in flight altitude (including 95\% confidence interval) relative to the mean flight altitude $(27.9 \mathrm{~m})$ over distance from the avian radar. Flight altitude was estimated using a generalized additive model, while controlling for the random effects of night-of-year and track ID. The grey line indicates the location of the UV lights

study. The test design consisted of UV-lights placed $2.5 \mathrm{~m}$ off the ground and pointing upwards; observed displacement is therefore also relative to ground level. However, when implemented, the UV-lights at a wind turbine have to be placed such that they encompass the rotor-swept zone; i.e. 50-100 $\mathrm{m}$ above ground level. To which extent displacement will occur at higher altitudes above ground level could not be answered by this study. Also, in order to be effective in deterring birds from the rotor swept zone of a wind turbine, most birds need to display avoidance along the entire rotor blade length $(40-50 \mathrm{~m})$. This study indicated that, given the lights used, only a proportion of birds avoided the lights to up to $30 \mathrm{~m}$ at a maximum. However, when the light is allowed to reflect off the surface of the turbine blades, e.g. using a UV-reflective coating (Young et al. 2003), it is possible that this would extend the range of the deterring effect, compared to this experiment that used an isolated lamp.

To increase the efficacy of the UV lights to deter birds from the area, this necessitates that the energy emitted from the lights are diffused as little as possible, using either higher output or a beam that is as narrow as possible. However, with increased irradiance (Watt $/ \mathrm{m}^{2}$ ) and/ or narrower beam width, also the minimum safety distances increase within which eye damage may occur. The efficacy of UV light as a deterrence measure likely also depends on the solar irradiance levels to reach abovesolar threshold values. The time-period when lights emit more UV-light than the sun, diminishes towards midday and varies seasonally. This likely also varies at different latitudes with higher solar irradiance towards the equator but more variable daytime periods at higher latitudes.

Lastly, in practical applications, potentially harmful ecological effects of UV light pollution should be considered, such as attraction of insects (van Langevelde et al. 2011). Attraction of insects may in turn attract birds, and especially bats, to the wind turbines resulting in increased 
Table 2 Groundtruthed avian radar tracks to species (group) during the testing period

\begin{tabular}{|c|c|c|c|c|}
\hline \multirow[t]{2}{*}{ Species (group) } & \multirow[t]{2}{*}{ UVS sensitivity } & \multirow[t]{2}{*}{ Number of individuals } & \multicolumn{2}{|c|}{ Altitude (m) } \\
\hline & & & Mean & SD \\
\hline Large gulls species & UVS & 282 & 9.2 & 14.1 \\
\hline White-tailed Eagle (Haliaeetus albicilla) & (VS) & 13 & 5.6 & 2.3 \\
\hline Eider Duck (Somateria mollissima) & (VS) & 28 & 5.7 & 0.6 \\
\hline Eurasian Curlew (Numenius arquata) & (VS) & 2 & 5.5 & \\
\hline Eurasian Oystercatcher (Haematopus ostralegus) & VS & 20 & 5.5 & 0.0 \\
\hline Small gulls species & UVS & 14 & 24.0 & 60.8 \\
\hline Diving ducks (Aythyinae spp.) & (VS) & 26 & 5.2 & 2.2 \\
\hline Total & & 385 & 9.2 & 17.4 \\
\hline
\end{tabular}

The second column indicates the species sensitivity within the (ultra)violet spectrum, as derived from (Håstad et al. 2005; Ödeen et al. 2010; Ödeen and Håstad 2013).

Sensitivity indicated in brackets are indicative and derived from species within the same phylogenetic family

Table 3 Comparison of model parsimony for contrasting models explaining effects of UV light (365 and $400 \mathrm{~nm}$ ) on flight altitude

\begin{tabular}{|c|c|c|c|c|c|c|c|c|c|}
\hline Model & Covariates & df & AIC & $\Delta \mathrm{AIC}$ & logLik & Deviance & $x^{2}$ & $x d f$ & $p$ \\
\hline III & UV_TYPE*Distance & 11 & 136.18 & 0.00 & -57.09 & 114.18 & & & \\
\hline V & UV_TYPE*Distance*NOY & 17 & 139.44 & 3.26 & -52.72 & 105.44 & 8.74 & 6 & 0.189 \\
\hline$\|$ & UV_TYPE & 8 & 152.65 & 16.47 & -68.33 & 136.65 & 31.21 & 9 & $<0.001$ \\
\hline I & $<$ intercept> & 6 & 154.72 & 18.54 & -71.36 & 142.72 & 6.07 & 2 & 0.048 \\
\hline IV & UV_TYPE*NOY & 11 & 156.60 & 20.42 & -67.30 & 134.60 & 8.12 & 5 & 0.150 \\
\hline
\end{tabular}

The last three columns represent log-Likelihood tests between consecutive models. NOY indicates night-of-year

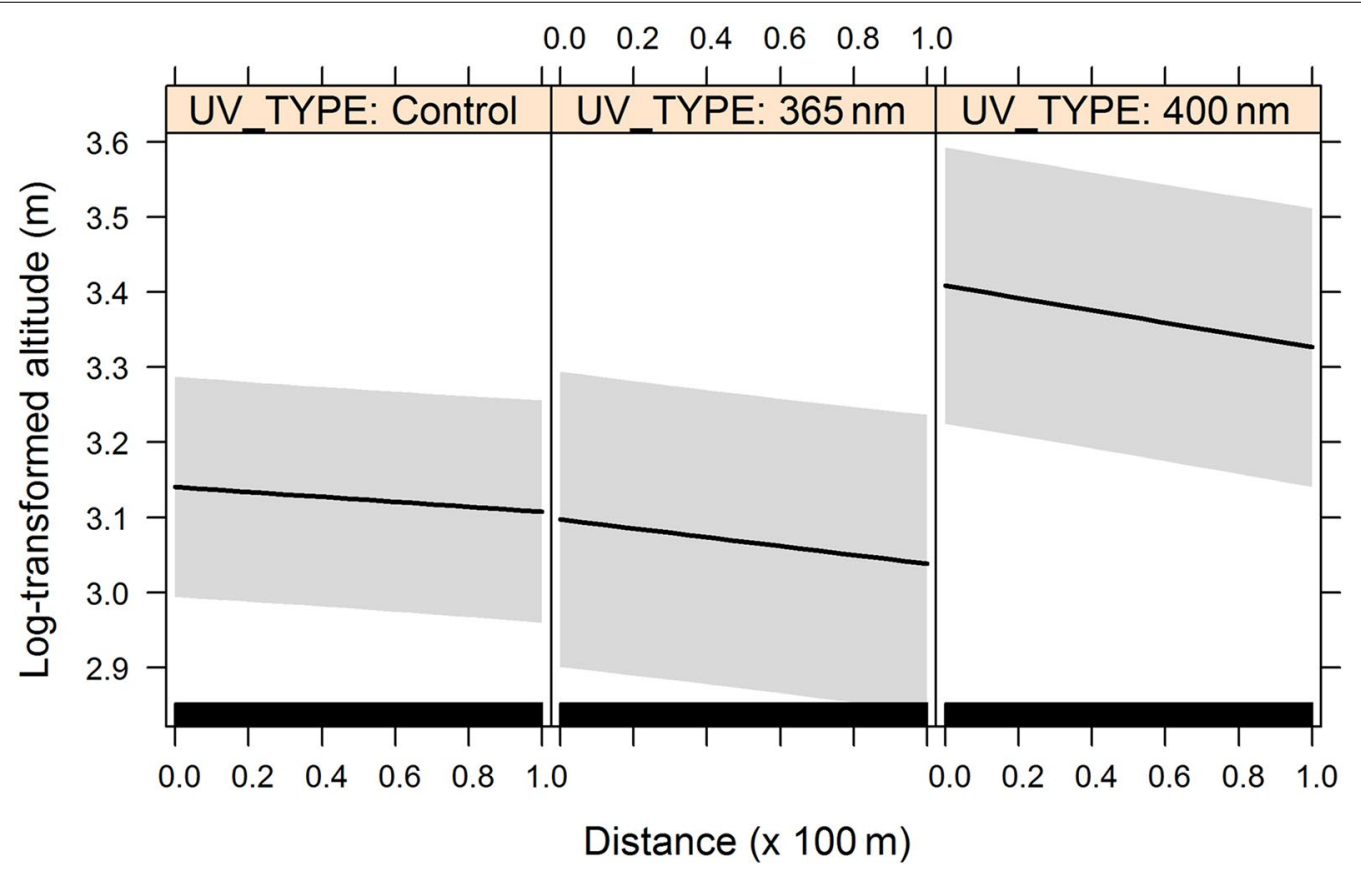

Fig. 3 Mean regression estimates and 95\% confidence interval for the most parsimonious model explaining effects of UV light (365 and $400 \mathrm{~nm}$ ) and distance on flight altitude 
Table 4 Comparison of model parsimony for contrasting models explaining effects of UV light ( 365 and $400 \mathrm{~nm}$ ) on flight activity

\begin{tabular}{|c|c|c|c|c|c|c|c|c|c|}
\hline Model & Covariates & df & AIC & $\triangle \mathrm{AIC}$ & logLik & Deviance & $x^{2}$ & $x d f$ & $p$ \\
\hline IV & Distance + Altitude*UV_TYPE & 21 & 7582.9 & 0.0 & -3770.4 & 7540.9 & & & \\
\hline V & $($ Distance + Altitude)*UV_TYPE & 29 & 7597.7 & 14.8 & -3769.8 & 7539.7 & 1.18 & 8 & 0.997 \\
\hline । & Distance + Altitude & 11 & 7604.7 & 21.8 & -3791.4 & 7582.7 & 43.04 & 18 & $<0.001$ \\
\hline$\|$ & Distance + Altitude + UV_TYPE & 13 & 7607.1 & 24.2 & -3790.5 & 7581.1 & 1.63 & 2 & 0.442 \\
\hline III & Altitude + Distance*UV_TYPE & 21 & 7620.6 & 37.7 & -3789.3 & 7578.6 & 2.46 & 8 & 0.964 \\
\hline
\end{tabular}

The last three columns represent log-Likelihood tests between consecutive models
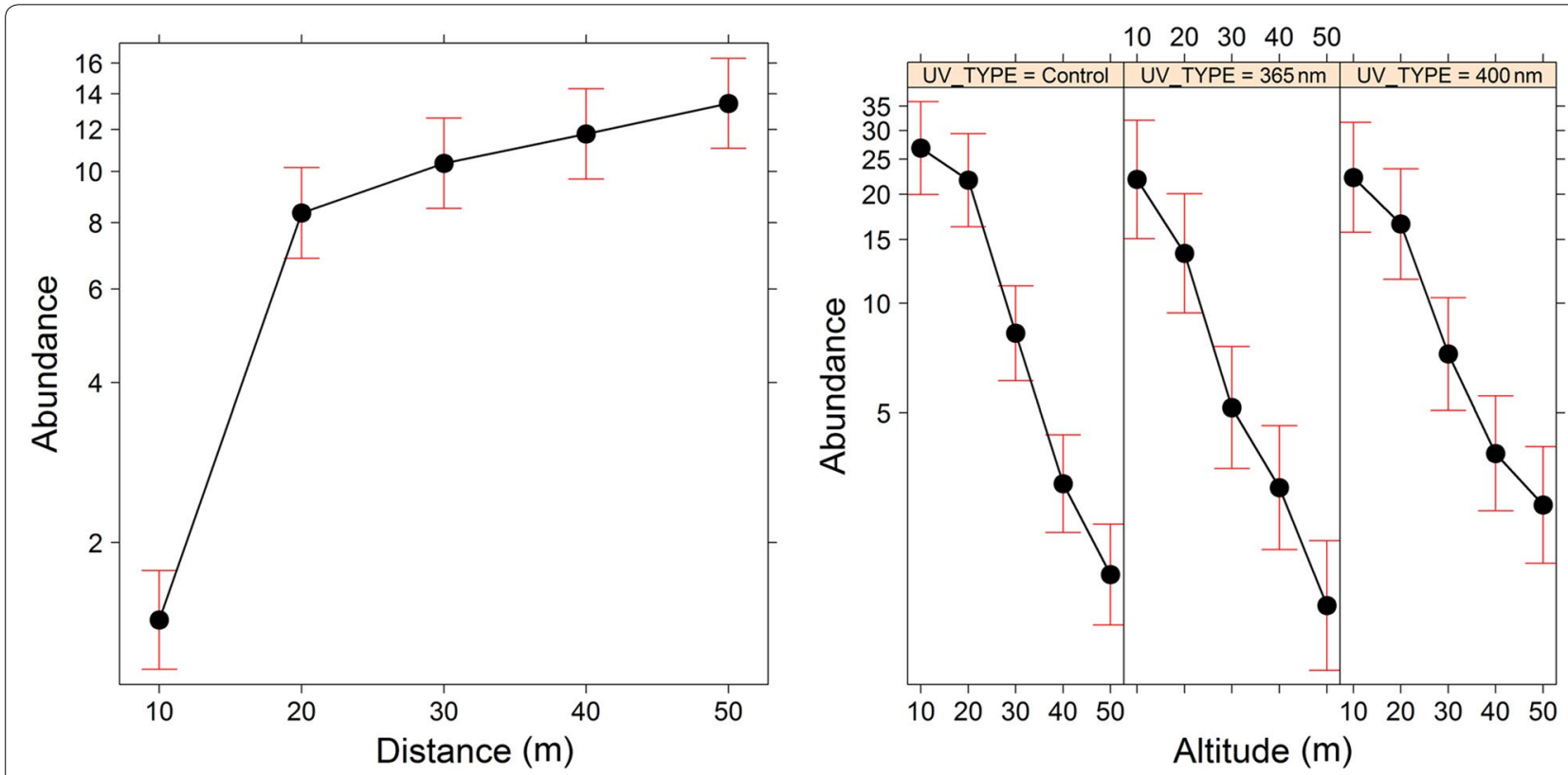

Fig. 4 Mean regression estimates and 95\% confidence interval for the most parsimonious model explaining effects of UV light (365 and 400 nm) on flight activity. Left panel: effect of distance from the lighting set-up on abundance; right panel: effect of UV light on the abundance at different altitudinal categories

collision risk in these species. Based on this pilot study, we recommend that further research is required investigating physiological vision damage distance thresholds in birds and humans (dependent on how the lights will be directed), testing behavioural responses in birds to other lighting regimes (e.g. narrower beam width or laser, moving or flickering beam) in combination with potential side effects (e.g. insect attraction, light pollution). This pilot study has shown that birds were partially displaced by UV-light within a limited distance range, which may allow the development of mitigation designs only encompassing the rotor swept zone potentially combined with a triggering system to minimize habituation (May et al. 2015). This may in turn, when tested successfully in situ, help reduce collision risk while maintaining utilization of the area in-between the wind turbines by birds.

\section{Conclusions}

Vision is the primary sensory system in birds, which for a number of species also includes the ultraviolet spectrum. Many bird species that are known to collide with offshore wind turbines are sensitive in the violet or ultraviolet spectrum. For species that are mainly active at lower ambient light levels, UV lighting may deter birds from the lit area. However, we do not know whether UVsensitive birds in flight actually respond behaviorally to UV lights. In this study we found that, relative to control nights, bird flight activity was reduced within the lit area when the (ultra)violet light was on. In addition, the avian radar based data showed a limited vertical displacement in flight altitude which persisted over the season below $40 \mathrm{~m}$ above sea level. Still, with regard to implementation, we argue there still is a long way to go before a potentially 


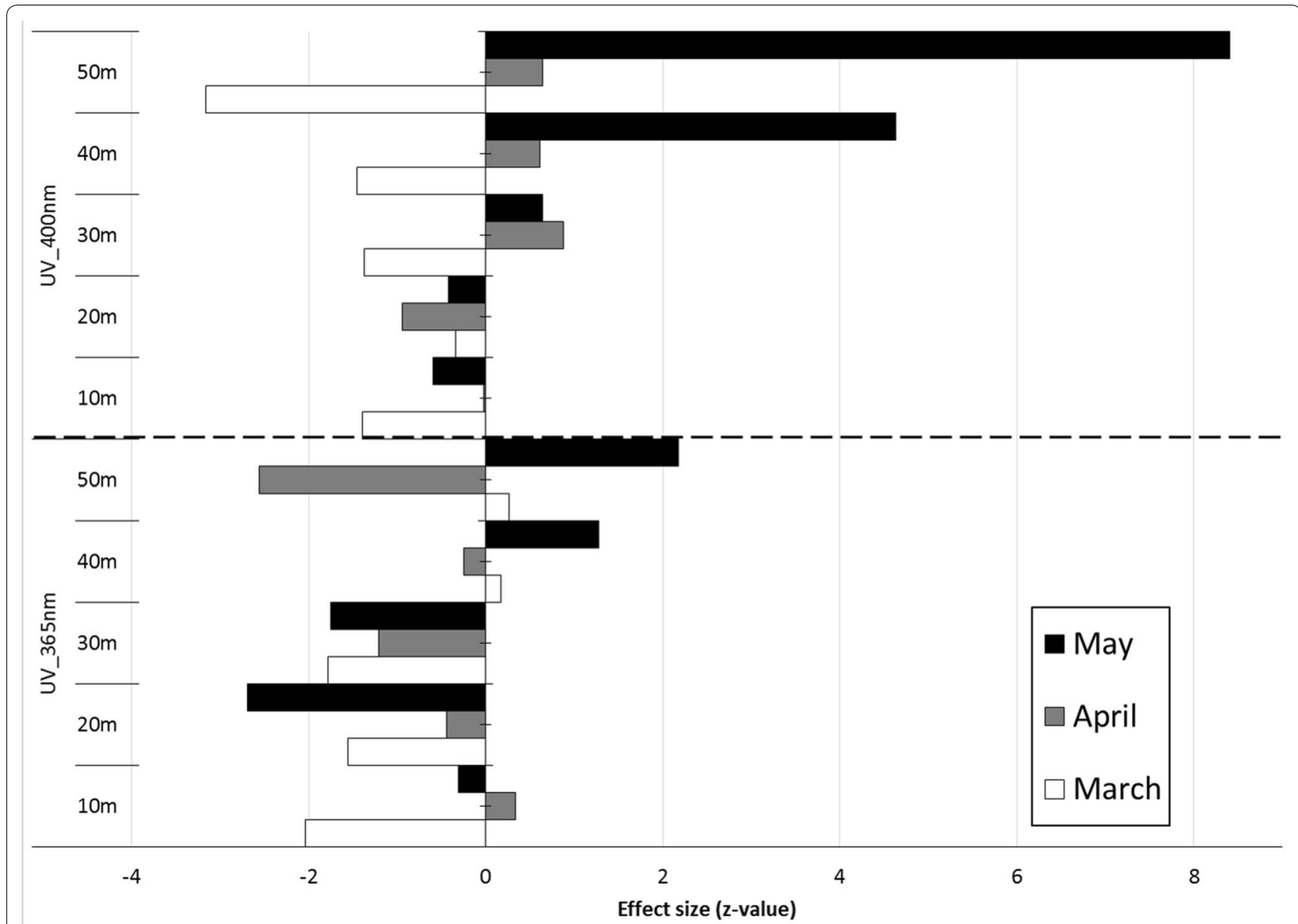

Fig. 5 Effect size of UV light (365 and $400 \mathrm{~nm}$ ) on flight activity at different altitude bands within different months. Negative values indicate lower activity; $z$ values beyond \pm 2 represent significant deviations from random

functional design to mitigate collisions at offshore wind turbines that has proven to be effective in situ may be in place.

\section{Additional files}

Additional file 1: Figure S1. Spectrogram for the 365 and $400 \mathrm{~nm}$ wavelength, measured at the avian radar system using Skye Instruments UV sensors.

Additional file 2: uvdata.xlsx. Excel file containing the raw input data on which the analyses were based.

Additional file 3: UV_analysis.R. R script which runs all of the analyses in the paper and produces the figures.

\section{Authors' contributions}

RM contrived the study design, contributed to the statistical analyses of the data and wrote the manuscript. J $\AA$ contributed to the analyses of the avian radar data and contributed to the manuscript. ØH and ELD carried out the field experiment, setting up and monitoring the avian radar system, and also helped with data preparation and the manuscript. All authors read and approved the final manuscript.

\section{Author details}

${ }^{1}$ Terrestrial Ecology Department, Norwegian Institute for Nature Research (NINA), Trondheim, Norway. ${ }^{2}$ Present Address: Steinøysund, Smøla, Norway.

\section{Acknowledgements}

We would like to thank Martin Professional for supplying us with the UV-lights free of charge. We would also like to thank Bjarke Laubek for supporting us in arranging the UV-lights and shipping them to us. We would also like to thank the INTACT steering committee for their input concerning study design and outcome.

\section{Competing interests}

The authors declare that they have no competing interests.

\section{Availability of data and materials}

All data analyzed during this study are included in this published article in supplementary information files.

\section{Consent for publication}

Not applicable.

Ethics approval and consent to participate

Not applicable. 


\section{Funding}

This study was executed as part of the Innovative Mitigation Tools for Avian Conflicts with wind Turbines (INTACT) project. This project was financed by a consortium consisting of the Research Council of Norway (Grant 226241), Vattenfall, Statkraft, Statoil, Energy Norway, TrønderEnergi Kraft, Norwegian Water Resources and Energy Directorate and NINA.

Received: 29 September 2017 Accepted: 3 December 2017

Published online: 19 December 2017

\section{References}

Bennett ATD, Cuthill I. Ultraviolet vision in birds: what is its function? Vis Res. 1994;34:1471-8.

Bevanger K, Berntsen F, Clausen S, Dahl EL, Flagstad Ø, Follestad A, Halley D, Hanssen F, Johnsen L, Kvaløy P, Lund-Hoel P, May RF, Nygård T, Pedersen H-C, Reitan O, Røskaft E, Steinheim Y, Stokke BG, Vang R. Pre- and postconstruction studies of conflicts between birds and wind turbines in coastal Norway (BirdWind). Report on findings 2007-2010. Trondheim: Research NIfN; 2010.

Bischof H-J, Niessner C, Peichl L, Wiltschko R, Wiltschko W. Avian UV/violet cones as magnetoreceptors. The problem of separating visual and magnetic information. Commun Integr Biol. 2011;4:713-6.

Blackwell BF, Bernhardt GE. Efficacy of aircraft landing lights in stimulating avoidance behavior in birds. J Wildl Manag. 2004;68:725-32.

Blackwell BF, DeVault TL, Seamans TW, Lima SL, Baumhardt P, Fernandez-Juricic E. Exploiting avian vision with aircraft lighting to reduce bird strikes. J Appl Ecol. 2012;49:758-66.

Blackwell BF, Fernandez-Juricic E, Seamans TW, Dolan T. Avian visual system configuration and behavioural response to object approach. Anim Behav. 2009;77:673-84.

Cole SG. Wind power compensation is not for the birds: an opinion from an environmental economist. Restor Ecol. 2011;19:147-53.

Cook ASCP, Ross-Smith VH, Roos S, Burton NHK, Beale N, Coleman C, Daniel H, Fitzpatrick S, Rankin E, Norman K, Martin G. Identifying a range of options to prevent or reduce avian collision with offshore wind farms using a UKbased case study. Thetford: British Trust for Ornithology; 2011.

Doyle JM, Katzner TE, Bloom PH, Ji Y, Wijayawardena BK, DeWoody JA. The genome sequence of a widespread apex predator, the golden eagle (Aquila chrysaetos). PLoS ONE. 2014:9:e95599.

Drewitt $\mathrm{AL}$, Langston $\mathrm{RH}$. Collision effects of wind-power generators and other obstacles on birds. Ann NY Acad Sci. 2008;1134:233-66.

Furness RW, Wade HM, Masden EA. Assessing vulnerability of marine bird populations to offshore wind farms. J Environ Manag. 2013;119:56-66.

Gauthreaux SA, Belser CG. Effects of artificial night lighting on migrating birds. In: Rich C, Longcore T, editors. Ecological consequences of artificial night lighting. Washington: Island Press; 2006. p. 67-93.

Gove B, Langston RHW, McCluskie A, Pullan JD, Scrase I. Wind farms and birds: An updated analysis of the effects of wind farms on birds, and best practice guidance on integrated planning and impact assessment. Strasbourg: Europe Co; 2013.

Hunt WG, McClure CJW. Do raptors react to ultraviolet light? J Raptor Res. 2015;49:342-3.
Håstad O, Ernstdotter E, Ödeen A. Ultraviolet vision and foraging in dip and plunge diving birds. Biol Lett. 2005;1:306-9.

Intergovernmental Panel on Climate Change. IPCC special report on renewable energy sources and climate change mitigation. Cambridge: Cambridge University Press; 2011.

Jarvis JR, Taylor NR, Prescott NB, Meeks I, Wathes CM. Measuring and modelling the photopic flicker sensitivity of the chicken (Gallus g. domesticus). Vis Res. 2002;42:99-106.

Lehman RN, Kennedy PL, Savidge JA. The state of the art in raptor electrocution research: a global review. Biol Conserv. 2007;136:159-74.

Lind O, Mitkus M, Olsson P, Kelber A. Ultraviolet vision in birds: the importance of transparent eye media. Proc R Soc Lond B. 2014;281:20132209.

Marques AT, Batalha H, Rodrigues S, Costa H, Pereira MJR, Fonseca C, Mascarenhas M, Bernardino J. Understanding bird collisions at wind farms: an updated review on the causes and possible mitigation strategies. Biol Conserv. 2014:179:40-52.

Martin GR. Understanding bird collisions with man-made objects: a sensory ecology approach. Ibis. 2011;153:239-54.

Martin GR. Through birds' eyes: insights into avian sensory ecology. J Ornithol. 2012:153:S23-48.

May RF. A unifying framework for the underlying mechanisms of avian avoidance of wind turbines. Biol Conserv. 2015:190:179-87.

May R, Reitan O, Bevanger K, Lorentsen SH, Nygard T. Mitigating wind-turbine induced avian mortality: sensory, aerodynamic and cognitive constraints and options. Renew Sustain Energy Rev. 2015;42:170-81.

May R, Gill AB, Köppel J, Langston RHW, Reichenbach M, Scheidat M, Smallwood S, Voigt CC, Hüppop O, Portman M. Future research directions to reconcile wind turbine-wildlife interactions. In: Köppel J, editor. Wind energy and wildlife interactions: presentations from the CWW2015 conference. Cham: Springer; 2017. p. 255-76.

Osorio D, Vorobyev M. A review of the evolution of animal colour vision and visual communication signals. Vision Res. 2008;48:2042-51.

Ödeen $\mathrm{A}$, Håstad $\mathrm{O}$. The phylogenetic distribution of ultraviolet sensitivity in birds. BMC Evol Biol. 2013;13:36.

Ödeen A, Håstad O, Alström P. Evolution of ultraviolet vision in shorebirds (Charadriiformes). Biol Lett. 2010;6:370-4.

Ödeen A, Håstad O, Alström P. Evolution of ultraviolet vision in the largest avian radiation - the passerines. BMC Evol Biol. 2011;11:313.

Poot H, Ens BJ, de Vries H, Donners MAH, Wernand MR, Marquenie JM. Green light for nocturnally migrating birds. Ecol Soc. 2008;13:47.

R Core Team. Team: R: a language and environment for statistical computing Vienna: R Foundation for Statistical, Computing; 2015.

van Langevelde F, Ettema JA, Donners M, WallisDeVries MF, Groenendijk D. Effect of spectral composition of artificial light on the attraction of moths. Biol Conserv. 2011;144:2274-81.

Wiltschko R, Munro U, Ford H, Stapput K, Thalau P, Wiltschko W. Orientation of migratory birds under ultraviolet light. J Comp Physiol A Neuroethol Sens Neural Behav Physiol. 2014;200:399-407.

Young DP Jr, Erickson WP, Strickland MD, Good RE, Sernka KJ. Comparison of avian responses to UV-light-reflective paint on wind turbines. Subcontract report July 1999-December 2000. Golden: National Renewable Energy Laboratory; 2003.

\section{Submit your next manuscript to BioMed Central and we will help you at every step:}

- We accept pre-submission inquiries

- Our selector tool helps you to find the most relevant journal

- We provide round the clock customer support

- Convenient online submission

- Thorough peer review

- Inclusion in PubMed and all major indexing services

- Maximum visibility for your research

Submit your manuscript at www.biomedcentral.com/submit
C BioMed Central 